\section{HSE}

Historia Social y de la Educación

Social and Education History
Hipatia Press

www,hipotiapress.com

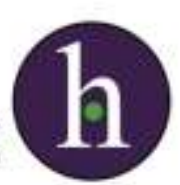

Instructions for authors, subscriptions and further details:

http://hse.hipatiapress.com

\title{
Editorial ZYX, S.A.: Editorial obrera contra el Franquismo
}

Mํㅡㄹ del Mar Araus ${ }^{1}$ y Ana Sánchez ${ }^{2}$

1) Universidad de Alcalá

2) Universidad de Valladolid

Date of publication: October $23^{\text {rd }}, 2015$

Edition period: October 2015-February 2016

To cite this article: Araus, M.M., y Sánchez, A. (2015). Editorial ZYX, S.A.: Editorial obrera frente al Franquismo. Social and Education History 4(3), 260-286. doi:10.17583/hse.2015.1729

To link this article: http://dx.doi.org/10.17583/hse.2015.1729

\section{PLEASE SCROLL DOWN FOR ARTICLE}

The terms and conditions of use are related to the Open Journal System and to Creative Commons Attribution License (CC-BY). 


\section{ZYX Editorial, SA.: Workers' Publishing House against "Franquismo"}

$\mathrm{M}^{\mathrm{a}}$ del Mar Araus

Universidad de Alcalá (España)
Ana Sánchez

Universidad de Valladolid

(España)

\section{Abstract}

Conducting a study of ZYX publishers involves submitting a historical document on the role of apostolic workers against francoism. The lack of a necessary study has meant that this event is unknown to date, not only signified an important apostolic experience but also an associative reality during francoism. It fought to foster awareness and democratic rights despite becoming a dictatorial state. The length of the document does not allow for an in-depth, comprehensive analysis of the development of the work carried out by the publishers over the years and up to their crisis and disappearance. Hence we will basically focus on presenting the publishers and most of all the first period of development, the essence of the ZYX publishing company.

Keywords: working culture, publishing working, ZYX editorial, adult education 


\section{Editorial ZYX, S.A.: Editorial Obrera contra el Franquismo}

$\mathrm{M}^{\mathrm{a}}$ del Mar Araus

Universidad de Alcalá (España)
Ana Sánchez

Universidad de Valladolid

(España)

\section{Resumen}

Realizar un estudio de la editorial ZYX supone presentar un documento histórico en la lucha del apostolado obrero frente al franquismo. Este acontecimiento, hasta ahora no sacado a la luz por la carencia de un estudio a fondo, no sólo supuso una importante experiencia apostólica, sino una realidad asociativa durante el franquismo. Luchó por la creación de conciencia y por las libertades democráticas a pesar de protagonizarse en un estado dictatorial. La extensión no permitirá un análisis profundo y exhaustivo del desarrollo y labor desempeñada por la editorial a lo largo de los años, hasta su crisis y desaparición. Por ello nos centraremos básicamente en hacer una presentación de la editorial y sobre todo, en la primera época, la que corresponde, de manera propiamente dicha, a la Editorial ZYX.

Palabras clave: cultura obrera, editoriales obreras, editorial ZYX, educación de personas adultas 


\section{Araus y Sánchez - Editorial ZYX}

¿La miseria y la ignorancia son las principales plagas que sufre el pueblo? Pues guerra a ambas. Contra la ignorancia, escuelas, periódicos y libros; contra la miseria, asociación. (Lema de la Federación Regional Española de la I Internacional).

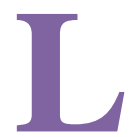

a editorial ZYX debemos enraizarla en la cultura obrera vivida en el siglo XIX y parte del siglo XX. En este sentido se hace necesario plantear una referencia a la importancia que tuvo la cultura obrera en la Historia del Movimiento Obrero. La prensa obrera y las editoriales de libros y folletos realizaron una labor fundamental en la transmisión de ideales y valores de lucha, además de crear una opinión pública esencial para el cambio de sociedad.

La cultura es uno de los aspectos más importantes que nos ha transmitido el movimiento obrero. La ignorancia les mantenía hundidos en la miseria y la toma de conciencia de esta realidad sembró en la clase trabajadora una profunda y permanente preocupación por la educación, tanto humana como profesional. Sólo era posible librarse de estas lacras protagonizando su vida, siendo gestores y organizadores de sus propias organizaciones, cultivando a su vez la conciencia, con una seria y profunda formación que les permitiera conocer la realidad, para tener capacidad de transformarla. Protagonismo, asociación y cultura serán los tres pilares para el gran edificio de la liberación.

Con el triunfo de las formas burguesas de producción, no sólo perdieron su condición social y profesional, sino que también vivieron una situación de miseria moral, espiritual y cultural; situación que les mantenía en la indignidad como personas. A partir del triunfo de la burguesía en el plano económico y en el plano político, el proletariado empezó a crear sus propias formas de organización y de acción y a superar los valores ideológicos de la democracia burguesa. Los obreros no tardaron en darse cuenta que la libertad jurídica era un derecho abstracto cuando los medios de producción estaban en manos de una minoría de capitalistas y que los valores de la 
revolución francesa de "fraternidad" y de "igualdad" perdían todo sentido en un mundo regido por el dinero y el poder material. Fue a partir de esa toma de conciencia cuando nace la cultura propiamente obrera. El proletariado creará formas de conducta y hábitos mentales radicalmente opuestos a los de la burguesía. La expresión más concreta se muestra en la creación de sociedades de resistencia y ayuda mutua, sindicatos, cooperativas de producción y de consumo, casas del pueblo, ateneos, escuelas obreras, teatros de aficionados, bibliotecas obreras, círculos culturales y, sobre todo, en una ingente proliferación de periódicos y publicaciones dirigidos y escritos exclusivamente por obreros. Otra manifestación original de la cultura obrera fue el empleo de la huelga, como medio de resistencia contra la explotación de los propietarios de fábricas (Saña, 1998, pp.71-72).

La fuerza central de la cultura proletaria arrancaba de la idea de que la vida del hombre sólo puede desarrollarse digna, humana e integralmente a partir de formas de organización social propiamente obreras. Esto se realizaría, según nos exponen Aguado, Molina y García (1977, p.82), mediante: a) Charlas, conferencias, cursillos, seminarios, diálogos, mítines, etc.; b) prensa obrera; c) libros obreros y editoriales obreras; d) centros culturales; e) planes de formación de las organizaciones obreras; y f) Propia lucha organizada de la clase obrera.

Muchas asociaciones fueron formadas para crear una opinión pública moral, reflexiva, enérgica, con la intención de crear bibliotecas y sociedades de discusión, obtener una prensa honesta y accesible económicamente a todos e instruir a hombres, mujeres y niños en una educación para la liberación. En locales insignificantes y en condiciones elementales celebran sus reuniones, leen sus folletos y periódicos, fundan sus sociedades de resistencia y luchan por un mundo más justo y humano.

El objetivo de muchos periódicos y libros que salieron a la luz era el de ser instrumentos de esta educación. Tenían como fin esencial la emancipación completa de la clase trabajadora (Araus, 1998, p.85). Estamos con Carlos Díaz en su afirmación de que la historia del movimiento obrero es en su hondón la historia de una emancipación cultura (Díaz, 1996, p.164). Para el movimiento obrero, las mejoras materiales como objetivo de su lucha eran absolutamente inseparables de lo que siempre fue el verdadero tesoro de la clase trabajadora: el afán por la cultura, desde la formación y la 


\section{Araus y Sánchez - Editorial ZYX}

promoción. "El signo específico y decisivo del proletariado no fue su lucha económica contra la burguesía, sino los valores espirituales, humanos y éticos e intelectuales creados por los obreros en el transcurso de esa lucha" (Saña, 1998, p.74). En esta línea se encuentra también el pensamiento del fundador de la Juventud Obrera Católica (JOC), Joseph Cardijn, que ya en 1921 precisaba que "el movimiento obrero es el esfuerzo colectivo y organizado de los obreros mismos, de la clase obrera misma, que trabaja de manera autónoma e independiente por su promoción material, económica, intelectual, moral, social y política" (Meert y Malagón, 1968, p.14). Es decir, que la promoción de la clase obrera no puede ni debe restringirse a una mejora de ciertas condiciones materiales de vida, sino que va mucho más allá, a un nivel moral y espiritual que les hiciera más personas.

Sin la prédica y presencia del diario y las editoriales de libros, en torno a los cuales y para su sostén se reunieron siempre militantes abnegados, capaces de todo sacrificio, no se sabría explicar el desarrollo y orientación del movimiento obrero. Incluso los obreros analfabetos, que no estaban en condiciones de leer periódicos, libros o folletos, procuraban instruirse y superar su ignorancia acudiendo a los mítines, conferencias y a las reuniones de sus compañeros. Juan Díaz del Moral, al referirse a la sed de aprender que reinaba, escribe:

Se leía siempre, la curiosidad y el afán de aprender eran insaciables, hasta de camino, cabalgando en caballerías, con las riendas o cabestros abandonados, se veían campesinos leyendo; en las alforjas, con la comida, iba siempre algún folleto... Es verdad que el 70 u 80 por ciento no sabía leer; pero el obstáculo no era insuperable. El entusiasta analfabeto compraba su periódico y lo daba a leer a un compañero, a quien hacía marcar un artículo más de su gusto; después rogaba a otro camarada que le leyese el artículo marcado, y al cabo de algunas lecturas terminaba por aprenderlo de memoria y recitarlo a los que no lo conocían (Díaz del Moral, 1973, p.188).

Colaborar en un órgano de expresión o en la difusión de libros era un compromiso en el que había que exponer toda la vida, jugarse todo, pues 
estaba en juego el más alto valor e ideal: la formación de la clase obrera (Araus, 1998, p.85).

Para ver la importancia que tenían las editoriales y periódicos, vamos a remitirnos a las palabras de Diego Abad de Santillán, militante que formó durante muchos años parte del grupo editor del periódico La protesta humana ${ }^{1}$ :

Todos los que hacían el periódico tomaban su responsabilidad en serio, y a esa función lo sacrificaban todo: si era necesario también la vida. Pero no había esa conciencia en los redactores y administradores solamente, sino también en el personal de los talleres, jóvenes y no jóvenes. Cuando era necesario, cuando había que afrontar una crisis, una dificultad, también el personal obrero renunciaba al horario habitual y al salario. Así se formó como una vasta familia solidaria y en ella se vivía y sufría a gusto.

El diario no publicaba avisos comerciales: se mantenía con la ayuda de los suscriptores, con la laboriosidad de los paqueteros y con el trabajo de imprenta para los sindicatos afines. El diario era algo sagrado para todos y habría más probabilidad de tener que darle mucho más de lo que de él se percibía para sobrevivir precariamente. No sólo no había con qué remunerar al personal gráfico, y por descontado, a la redacción y a la administración, sino que había que contentarse con una especie de rancho de cuartel o de prisión para sostenerse en pie y continuar en aquella trinchera.

Como nuestra vida material era comúnmente mísera, algunos amigos cuyo standard de vida era más holgado, nos hacían llegar prendas de vestir todavía presentables, que no solían ajustarse al pie de los nuevos usuarios, con las consiguientes consecuencias (Abad de Santillán, 1977, p.55).

A lo largo del siglo XIX y principios del XX, la propaganda, editoriales, en definitiva la cultura, se hará mucho más fecunda y combativa. Se fundaron numerosas bibliotecas populares en ciudades grandes y pequeñas, fundadas y sostenidas por militantes, y sería digna de evocación la cantidad de escuelas fundadas, sin contar los sindicatos, establecidos a veces hasta en 


\section{Araus y Sánchez - Editorial ZYX}

los lugares más apartados. La tónica dominante en esas creaciones era la siguiente: procurar por todos los medios hábiles la formación entre los asociados y sobre todo recomendar la abstinencia de bebidas alcohólicas por ser no sólo perjudicial para el hombre, sino también causa de inmoralidad. Las bibliotecas y escuelas estuvieron estrechamente ligadas a la organización obrera (Abad de Santillán, 1977, p.50).

Son años en los que la organización obrera funcionaba sin libertad. Se vivía bajo la represión policial y de las leyes. Sus locales eran asaltados con frecuencia, destruidos sus muebles y quemadas sus bibliotecas. Esto inspiraba nuevas formas de propaganda y una agilidad y dinamismo tal que había folletos y periódicos que aparecían y desaparecían de un día para otro.

Esta experiencia fue vivida por los militantes, de origen obrero, que pusieron en marcha la editorial ZYX. Valores como el sacrificio, la amistad, la solidaridad, la justicia, la autogestión y el amor al prójimo... encarnado en sus vidas fue lo que hizo posible que soportaran la persecución, cárcel, hambre y las carencias de las necesidades más básicas de un estado totalitario que perseguía a muerte cualquier realidad de promoción del pueblo.

\section{ZYX: Apostolado Obrero frente al Franquismo}

Junto a la corriente de cristianos colaboradores con el franquismo, hubo en España, desde 1943, otra corriente de cristianos que, por razón evangelizadora y apostólica, lucharon por las libertades democráticas y promocionaron instrumentos de primera importancia para la emancipación social $^{2}$.

Desde 1942 y en el marco de la Acción Católica de hombres, empiezan a constituirse secciones de Apostolado Obrero, iniciadas por medio de cursos de verano para trabajadores procedentes de distintas diócesis (en 1942 en Cófredes, en 1943 en Vigo). En años posteriores aparecerían otras asociaciones dentro de la Acción Católica que acabarían por agruparse, como la Hermandad Ferroviaria de la Acción Católica, que constituyó en 1944 el Obispo de Ciudad Real Emeterio Echevarría; en ese mismo año se inició el sacerdote D. Tomás Malagón, que había trabajado en ambientes 
obreros durante la guerra en el frente de Andalucía y que desde 1954 será Consiliario de la HOAC (Hermandad Obrera de Acción Católica).

En 1946, la Acción Católica, funda los movimientos especializados de Apostolado Obrero. Los obreros habían estado alejados de la Iglesia desde el siglo XIX, el reencuentro de la clase obrera con la Iglesia era una asignatura pendiente. Podemos afirmar, con toda certeza, que el apostolado obrero va a ser un movimiento misionero que va a hacer posible tender los puentes entre la Iglesia y la clase obrera (Gómez del Castillo, 1987, p.6). Bajo ese prisma nacen la HOAC (Hermandad Obrera de Acción Católica) en 1946 y la JOC (Juventud Obrera Cristiana) en 1947. La articulación de la HOAC y de la JOC había sido propiciada por la terminación de la Segunda Guerra Mundial. En una audiencia que concedió en 1946 al primado español, el Papa Pío XII insistió a Pla i Deniel en la conveniencia de comenzar esa labor. El 4 de mayo en la revista Ecclesia se publican las Normas de especialización del Apostolado Obrero de la Acción Católica ${ }^{3}$.

Se inicia así un movimiento de apostolado obrero militante que nacerá en España por voluntad del Papa, con la incomprensión de muchos cristianos (obispos incluidos) y la oposición firme de muchos políticos (tanto de democristianos colaboradores con el franquismo como de progresistas o socialistas). Así, Gómez del Castillo cita cómo Monseñor Eijo Garay se niega a aceptar el proyecto y funda en su Diócesis las Hermandades del Trabajo ligadas a la Organización Sindical (Gómez del Castillo, 1987, p.8). La clave de la HOAC fue el núcleo de militantes conversos, procedentes en su mayoría del socialismo, anarcosindicalismo y comunismo; sin ellos no podría entenderse ni habría sido posible la militancia obrera.

La HOAC se acoge a las Normas de Especialización del Apostolado Obrero de la Acción Católica. Esto significaba un mayor grado de autonomía, la posibilidad de administrar más o menos libremente sus fondos, disponer de consiliarios propios, editar publicaciones propias periódicas sin someterse a la censura, ni al sistema de prensa y la posibilidad de establecer una organización a escala nacional. Al principio, los presidentes y consiliarios debían ser nombrados por los organismos centrales de la Acción Católica, pero en 1949 se lleva a cabo un cambio especialmente significativo y se acentúa el carácter estrictamente obrero. 


\section{Araus y Sánchez - Editorial ZYX}

En la HOAC fue decisiva la acción militante aportada por Guillermo Rovirosa, ingeniero y brillante investigador. Vivió en las empresas colectivizadas de la zona republicana el espíritu de la militancia obrera y fue hijo de un proceso religioso de conversión, con una vida de pobreza total.

En el marco de la acción apostólica, la HOAC contará con una serie de medios y plataformas (Díaz, 1996, pp.421-425) fundamentales para la promoción personal y colectiva, muchos de los cuales serán también utilizados posteriormente por la editorial ZYX. Algunos de los más importantes fueron los siguientes:

a) Cursillos nocturnos: para concienciar sobre los problemas obreros.

b) Cursillo apostólico: se planteaba el paso a la fe cristiana. Se forjaba un tipo de laico comprometido, dando la imagen de un tipo de cristianismo muy distinto al imperante.

c) Los GOES (Grupos Obreros de Estudios Sociales): se dividían en economía, sindicalismo y política. A partir de la mitad de la década de los 50 se inició la apertura de los GOES a los militantes de organizaciones de izquierda y a gente interesada, aunque no fueran de la HOAC. En 1965, 100 grupos de GOES políticos debatían el tema de una Constitución Federal para España.

d) Cursillos sobre historia del movimiento obrero: los militantes obreros cristianos introdujeron clandestinamente en el país la historia del movimiento obrero escrito en castellano y prohibido por la censura. Abierto a todos los obreros.

e) Cursillos de política: analizaban el tema de los partidos políticos y su importancia para la clase obrera.

f) Hojas informativas de los conflictos laborales: muchos militantes de la HOAC participan como organizadores de los conflictos de la clase trabajadora de una forma muy destacada en las huelgas mineras de Asturias, Vizcaya y Guipúzcoa, regiones en las cuales llega a decretarse el estado de excepción en 1962. Tuvieron un papel destacado en la llamada "huelga de Bandas". La aparición de las primeras hojas informativas dotó al conflicto de un elemento de vital importancia; la utilización de un medio de información diario contribuyó decisivamente al mantenimiento de la huelga y a la 
extensión de la red de solidaridad que trascendió incluso fuera de la provincia (Pérez, 1999, p.32). Esta huelga es llevada a cabo por los trabajadores de la Empresa de Laminación de Bandas en Frío de Echevarri (Bilbao) y será una de las más importantes y largas emprendidas durante el régimen de Franco (duró 5 meses, del 30 de noviembre de 1966 hasta el 1 de mayo de 1967) ${ }^{4}$.

g) Fondo de Solidaridad: han existido huelgas y conflictos sostenidos por la HOAC.

h)Periódico ¡TÚ!: sale a la calle el 15 de noviembre de 1946, con una periodicidad quincenal y una tirada de 5.000 números. En abril del 1947 pasa a 6.000, en octubre a 8.000 y en febrero de 1948 alcanza los 13.000. Cuanto más crece la represión del régimen, más crece su difusión. El 1 de enero de 1949 sale con periodicidad semanal y en noviembre de 1949 la tirada asciende ya a 34.000 ejemplares. El 17 de marzo de 1951 es prohibida por el régimen franquista, cuando ya había alcanzado la cifra de 40.000 ejemplares de tirada. Había alcanzado el segundo puesto de las publicaciones periódicas semanales. Es reseñable el juicio emitido sobre ¡TÚ! por el gobernador civil de Huesca:

El semanario ¡TÚ!, que se autodetermina órgano de Acción Católica, viene haciendo una campaña insidiosa contra el régimen y el gobierno, o al menos contra alguno de sus Ministros. La campaña, con la procacidad del estilo, la ligereza de sus juicios, y lo inexacto de muchas de sus afirmaciones, no se diferencia mucho que la del extranjero hacen 'Solidaridad Obrera' y 'Mundo Obrero (Navarro-Ruiz Camps, 1993, p.26-35).

i) Boletín de la HOAC: hasta 1953 se llamó "Boletín de Dirigentes", para ayudar a la reflexión y formación de los militantes.

j) Plan Cíclico: surgido por una remodelación conjunta entre Guillermo Rovirosa y D. Tomás Malagón a partir de 1954. Tiene una duración de tres años, a lo largo de los cuales se debía ir formando la conciencia cristiana, desde el Evangelio y la Doctrina Social de la Iglesia (López, 1995, pp.61-64). 
k) Equipos de dolor: eran equipos de enfermos, organizados dentro de los hospitales de tuberculosis, que debían permanecer largo tiempo en el hospital. Ofrecían su dolor y enfermedad por la labor apostólica de la HOAC (Díaz, 1996, pp. 421-425).

Como recuerda Berzal de la Rosa (1999, p.155), junto a estas plataformas tendrán lugar otra serie de realizaciones más vinculadas a equipos concretos de militantes, fundamentalmente en la primera mitad de los años cincuenta, cuando, impulsadas por la HOAC, surgirían las primeras cooperativas de consumo, producción y viviendas, destinadas a materializar el ideal sociolaboral expuesto por Guillermo Rovirosa (una concreción del mismo será la desarrollada precisamente en el primer libro que publica la Editorial ZYX: “¿De quién es la empresa?”, así como las experiencias que se desarrollaron en el marco de las Sociedades Anónimas Laborales).

De esta manera se hizo frente a la apostasía de la clase obrera, tendiendo puentes de diálogo entre la Iglesia y la clase obrera. Esta tarea se realizaría mediante una serie de elementos fundamentales para la promoción de los trabajadores como:

a) Ateneos obreros: de forma incipiente y clandestina ya desde 1943 y de forma pública a partir de 1947, bajo el nombre de "Cultura Social Obrera".

b) Instrumentalización del sindicalismo vertical franquista (mediante la penetración en las elecciones y la creación de bufetes laboralistas desde 1947, ambas, piezas fundamentales para la propia existencia de lo que más tarde sería Comisiones Obreras).

c) Nuevas formas de cooperativismo, a raíz de la aprobación de la ley de sociedades anónimas, siendo el germen de las Sociedades Anónimas Laborales (SAL). En este sentido hay que tener también muy presente la potenciación de cooperativas por parte de militantes cristianos.

d) Oposición frontal a los partidos políticos confesionales y presencia posterior en agrupaciones como el Frente de Liberación Popular (FELIPE), de los que también se discreparía pronto, debido al autoritarismo marxista que se respiraba en ellos. 
En la década de los 60, llega la primera gran crisis del apostolado obrero español. Un tema reseñado por diversos autores y reconocido en numerosos estudios sobre la Iglesia y sobre el Franquismo. Antes del estallido de esta crisis (llamada también crisis profranquista), y en previsión de la misma, un grupo de militantes de la HOAC lanzaron la editorial ZYX, junto a Guillermo Rovirosa -su primer presidente-, como organización de apostolado privado. La editorial ZYX se convertirá en la editorial obrera por excelencia durante el franquismo. Contribuyó y forzó a que a la HOAC se le concediera, en 1966, un Estatuto especial dentro de la Acción Católica española ligándose directamente a la Comisión Episcopal de Apostolado Seglar (Gómez del Castillo, 1987, p.18).

\section{Editorial ZYX, S.A.}

\section{¿Cómo Nace la Editorial ZYX?}

En el verano de 1963 se reunieron en Segovia un grupo de sacerdotes y militantes obreros que venían trabajando desde tiempo atrás en tareas de promoción del mundo del trabajo dentro de la HOAC. Los asistentes a aquel acto manifestaron las dificultades que estaban encontrando en el camino de la HOAC. Los hombres más representativos de la HOAC ya habían sido apartados, entre ellos Guillermo Rovirosa.

Todos los presentes acogieron con entusiasmo la idea de crear una asociación que permitiera llevar adelante la línea de promoción del pueblo que se había venido siguiendo por parte de los militantes obreros cristianos. Así fue como surgió la editorial ZYX, que toma el nombre de las tres últimas letras del abecedario y, además empezando por la última, al revés que el diario ABC (Gómez del Castillo, 1996), con lo que ya apunta dónde está su compromiso.

La editorial ZYX efectúa su lanzamiento a través de la acción del sacerdote D. Luis Capilla y del laico Julián Gómez del Castillo, que será su presidente desde 1964 hasta 1972; durante los primeros años D. Tomás Malagón estará en una postura de apoyo moral y Jacinto Martín ${ }^{5}$, desde Pola de Laviana, presta su colaboración decidida: será el autor del segundo libro publicado, Juventudes de hoy; dos años después, Teófilo Pérez Rey de 


\section{Araus y Sánchez - Editorial ZYX}

origen socialista, al igual que Julián Gómez del Castillo, dejará su postura expectativa y pasará también a la colaboración. Éstos son los que constituyen el núcleo inicial de ZYX y a los que habría que unir el grupo de los primeros delegados regionales y que fueron fundamentales en la expansión de ZYX. Estos militantes fueron los únicos sostenedores, en el orden moral y económico, de la editorial (Gómez del Castillo, 1987, p.18). Las conversaciones sobre la constitución de la editorial habrían sido iniciadas en Montserrat, cuando Guillermo Rovirosa fue visitado por D. Luis Capilla y Julián Gómez del Castillo: "Siempre recordaré nuestra visita a Montserrat para proponerle la idea. Me acompañaba don Luis Capilla [...]. Él se había resistido durante todo un día a salir de Montserrat; había sido excluido de la HOAC y encontraba en la abadía benedictina el calor y ambiente adecuados parta la contemplación, el trabajo y el estudio. Creo que había pensado concluir allí su tránsito por la Tierra. Aquella mañana, tras oír misa y desayunar, nos despedíamos en su habitación. Le dimos la última razón para que se uniera a nosotros en el lanzamiento de la "Editorial ZYX”: “Los pobres aún te necesitan”. Respuesta: “¿Cuándo salimos para Madrid?”. Una hora más tarde se encaminaba con nosotros a la capital de España” (Arbeloa, 1992, p. 75). Esta tesis vendría corroborada por las propias Noticias emitidas por Rovirosa desde Montserrat, concretamente en su "Noticia 24", donde anuncia su próxima marcha a Madrid, en agosto de 1963, ciudad en la que permanecerá hasta el 1 de diciembre, en lo que él denomina una intervención secundaria en la estructuración y constitución de la entidad Ediciones ZYX (Rovirosa, 1995, p.494), cuyos planes afirma que le entusiasman, manifestando su convencimiento de que "la cosa puede funcionar" en carta remitida a Xavier García fechada el 7 de noviembre de 1963 (Rovirosa, 2007, p.294).

El primer presidente de la editorial será Guillermo Rovirosa, que muere cuatro días después de ser presentado el primer libro ¿De quién es la empresa?, del que era autor él mismo. De este libro se venderían más de 20.000 ejemplares en varias ediciones (García, 1990). 


\section{Etapas por las que Pasa la Editorial ZYX}

La editorial pasará por varias $\operatorname{etapas}^{6}$ que pasamos a comentar a continuación:

$\boldsymbol{I}^{a}$ Etapa: 1964-1969: Cuando en febrero de 1964 sale a la calle el primer libro de la editorial, ésta acababa de fundarse. La editorial ZYX se constituye con algo menos de 300 personas, unas 180 de las cuales provenía de la HOAC ${ }^{7}$. Sostiene la editorial la aportación de 1.000 pts. que hacía cada uno de los socios, a los que unía su suscripción al libro de la colección «Lee y discute», serie roja, que valía 20 pts. y se editaba mensualmente. Otros socios además se hacían voluntariamente paqueteros (Gómez del Castillo, 1987, p.18). Serían considerados como suscriptores los que lo eran de los "Cuadernos Copin" (Cooperativismo Integral). El capital inicial del la editorial ZYX fue de 300.000 pesetas, fruto de muchas pequeñas aportaciones.

La labor editorial se desarrolla en torno a diversas colecciones, con precios populares que oscilan entre las 13 y las 100 pesetas (aunque en algún caso será un precio superior como son las 300 pesetas de "Dirección de ejercicios a militantes", libro excepcional, por sus dimensiones y encuadernación y del que no se hace la mínima mención en el folleto de la editorial). La temática marcará las líneas maestras de la editorial, abordándose libros en torno al sindicalismo e historia del movimiento obrero, política nacional y extranjera, economía, literatura social, compromiso cristiano,...

Al comienzo de este periodo funciona en el Ministerio de Información y Turismo (MIT) la consulta previa, vigente aún desde la ley promulgada en 1938 en plena Guerra Civil española y anterior a la famosa "Ley Fraga" de 1966, tras la cual se extiende esta primera etapa durante otros tres años ${ }^{8}$. Los libros de ZYX se venden en esta etapa de forma directa, entre suscriptores (que llegaron a 4.500), grupos y en la propia calle, a las puertas de las fábricas y de las parroquias obreras, en la universidad, gracias a pequeños puestos instalados por los militantes junto a colaboradores de la editorial. Así lo pone de manifiesto Gómez del Castillo (1996, p.18) cuando afirma que la editorial: 


\section{Araus y Sánchez - Editorial ZYX}

organizó su propia red distribuidora y de ventas, llegando a poner, un día del Libro, 60 puestos en Madrid y más de 400 en España, lo que hizo exclamar al profesor Ramón Tamames, entonces dirigente del PCE: «Tenéis la mejor infraestructura política de España».

El final de esta etapa viene marcado por el estado de excepción de 1969: desde el 24 de enero de dicho año se impide reiteradamente la publicación de libros por disposición del Ministerio de Información y Turismo. Tras seis meses de obligada inactividad, se propone combatir las pérdidas mediante algunos de los fines de la sociedad, como es el de la distribución general de fondos editoriales, para lo que se plantea aprovechar al máximo la capacidad organizativa y de gestión de ventas. Con esta finalidad la "Editorial ZYX" se reconvierte en una distribuidora y surgirá la Editorial ZERO.

$2^{a}$ Etapa: 1969-1974-1977: El propio año 1969 se presenta una nueva editorial para su inscripción en el Registro de Empresas Editoriales que obtiene con facilidad el número de registro, gracias al aval de sonoros apellidos como el de José Miguel Oriol, como él mismo relata en su obra "30 años de Encuentro. Memorias de una experiencia editorial" (Oriol, 2008). En esta etapa la editorial ZYX mantiene básicamente las mismas colecciones que en la etapa anterior, con pequeñas variaciones.

En este período debe enmarcarse la auténtica ruptura o desaparición de la editorial tal y como fue concebida y desarrollada en sus orígenes, fundamentalmente por la politización de la misma, entendida el sentido de la priorización de la tarea política (en la línea de los partidos políticos) sobre la labor apostólica con la que nació. Ya en la Circular de debate e información interna de 31 de diciembre de 1970 se destacaba que:

La editorial debe ser una organización política con una ideología y una línea clara en todos los frentes. Aclarando que esta organización política no se entiende como un partido al modo tradicional, sino como una organización que tiene algo que decir y debe decirlo en cuanto a acción política y sindical, dando una visión de conjunto.

En esta misma circular se debate el problema de la politización, rechazándose por todos la entendida como grupo o partido. 
Es precisamente en esta etapa cuando se produce la llegada a la editorial tanto de no creyentes, como de jóvenes, ajenos a los mundos del apostolado obrero, muy marcados por las corrientes políticas e intelectuales de la época. Esto conducirá a la grave escisión que se producirá en 1974, generada ya dos años antes. En 1972 ZYX se rompe como consecuencia de la existencia de una corriente mayoritaria que era partidaria de que fuera una organización de apostolado privado y otra corriente minoritaria que plantea hacerse organización política. De las16 delegaciones que tiene ZYX en España, 12 sostienen la postura apostólica y 4 la política. Gana la postura política y al año se expulsa a los miembros de la corriente apostólica; entre los que se quedan existe también una fuerte tensión interna, concluyendo en el lanzamiento de otras instituciones.

A pesar de que en esta etapa se ha producido ya la muerte de Franco y el advenimiento de la democracia a nuestro país, esto no significa que haya libertad, sino que continúa la labor de la censura, denegándose libros sometidos a consulta voluntaria y a las presentaciones de listas de libros para editar.

$3^{a}$ etapa: 1977-1980: Los libros dejan de ser vendidos en las calles y pasan a difundirse en librerías, junto con otras editoriales, con publicaciones de mayor extensión. Esto da muestra del completo cambio de rumbo de la aventura iniciada en 1963, que no se restringía a una mera publicación de obras, sino que buscaba una amplia labor cultural, de promoción y creación de conciencia. Ahora los autores de los libros que antes se publicaban y difundían están encuadrados en organizaciones legales: partidos, sindicatos,... asentados en la nueva democracia.

\section{¿Qué fue ZYX en sus orígenes?}

Como hemos señalado anteriormente, ZYX nace en 1963, con base jurídica de Sociedad Anónima para la lucha clandestina contra el franquismo. Se encuadraba, realmente, en una organización de apostolado privado, como en su día se manifestó al entonces arzobispo de Granada, D. Emilio Benavent Escuin (Malagón, 1999, pp- 26-31). Este hecho muestra una gran conciencia militante adulta por parte de los cristianos laicos que pusieron en marcha la 


\section{Araus y Sánchez - Editorial ZYX}

editorial, pues faltaban aún 20 años para que este tipo de asociación fuera reconocida oficialmente por la Iglesia ${ }^{9}$ tal y como matiza Teófilo Pérez Rey (1970):

Desde la fecha fundacional a la edición del primer libro; del comienzo, la creación, a la difusión por toda España; de la primera reunión a las que se suceden ya en todo lugar; desde el cero a la recaudación necesaria para empezar, se hace todo ello en un tiempo verdaderamente record.

Como ya hemos dicho, su primer presidente será Guillermo Rovirosa uno de los artífices de la red de difusión inicial de cara a las suscripciones. Apostará firmemente por la nueva editorial, proponiendo la suscripción directamente a los que en ese momento eran receptores de los "Cuadernos Copin":

propongo al destinatario de esta Noticia considerarle como suscriptor de los cuadernos ZYX como lo ha sido hasta ahora de los cuadernos Copin (estos últimos, como es natural, en adelante serán menos numerosos). No sé exactamente cuál será el precio de los cuadernos ZYX, solamente sé que oscilará alrededor de las 20 pesetas cada ejemplar, de unas cien páginas de texto. Si no me indican otra cosa yo les mandaré a reembolso dos ejemplares de cada cuaderno ZYX que vaya apareciendo; uno para el destinatario y otro para otra persona con la que se haya puesto de acuerdo para adquirirlo (Rovirosa, 1995, p. 494).

\section{Organización}

La editorial ZYX se constituye legalmente como una sociedad anónima, editora de libros y publicaciones, cuyos accionistas constituyen, al mismo tiempo, su red de distribución y que celebran sus reuniones de estudio en orden a los fines de la misma editorial. Noticia temprana de ellos nos encontramos ya en la Noticia 25 bis de Guillermo Rovirosa, en la que ya nos habla de los agentes difusores (Rovirosa, 1995, pp. 496-497).

Los accionistas se gobiernan por una Junta General de Accionistas (que se reúne anualmente), por un Consejo de Administración (que se reúne 
mensualmente y está formado por personas a las que se ha exigido garantías de fidelidad a los fines de la editorial) y por el Equipo Permanente (que celebra sus reuniones semanalmente).

Se pretende que la asamblea sea representativa, consultiva, deliberativa y abierta, características que se postularon y defendieron desde un primer momento. Sin embargo, para esto fuese una realidad se requiere una información y grado elevado de preparación de modo que se puedan tomar los acuerdos con la reflexión debida, reflexión que en muchas ocasiones se echaba, lamentablemente, en falta.

Como responsables de las actividades normales de la Editorial, hay un Gerente, un Director de Publicaciones (con un responsable para cada una de las secciones, dependiente de él), un equipo de ideología y estudio (organizado por una serie de colaboradores que analizaban los libros que se debían publicar), unos directores de cursillos, un Jefe de personal y un Delegado por cada región de España, dedicado exclusivamente a la Editorial. Según la citada conferencia dada por Teófilo Pérez Rey para la propia editorial, el 8 de febrero de 1970 (Pérez Rey, 1970):

las delegaciones nacen como un reflejo más fiel a la labor dinámica de creación inicial de la ZYX aun cuando hayan sido creadas bastante después. Se sustentan en personas de probada entrega, a las que se somete a un trabajo fuerte y a las que se les deja, prácticamente, a la propia iniciativa, una vez obtenido su compromiso.

Cada tres meses tiene lugar también una Reunión General, de dos días de duración, a la que asisten, al lado del pleno del Consejo de Administración, todos los Delegados de Zona y los principales colaboradores.

A modo de ejemplo, el equipo nacional de ZYX en noviembre de 1966 estaba constituido de la siguiente manera: a) Presidencia y publicaciones: Julián Gómez del Castillo; b) Centro de Ideología y Estudio (C.I.E.): D. Tomás Malagón, Jacinto Martín y Teófilo Pérez Rey; c) Comisión Económica:.José Molina, D. Luis Capilla y Teófilo Pérez Rey; d) Relaciones Internas: José Molina; e) Relaciones Públicas: Teófilo Pérez Rey; y f) Secretaría: Encarnación Sánchez. 


\section{Araus y Sánchez - Editorial ZYX}

\section{Colecciones y Series}

La editorial se estructura, como tal, en torno a diversas colecciones. El estudio realizado por Cisquella (2002), se refiere sólo a las series roja y verde de la colección «Lee y discute» y a las colecciones «Biblioteca Promoción del Pueblo» y «Se hace camino al andar», de la misma manera que la propia editorial, años después, haciendo un repaso histórico habla de que su andadura es iniciada por cuatro colecciones: «Lee y discute» (en sus dos series, roja y verde), «Promoción del pueblo», «Se hace camino al andar» y «Pueblo de Dios». Hasta el cambio de nombre de la editorial, es decir, hasta el estado de excepción de 1969 se publicarán 240 libros.

Rovirosa, el primer presidente, muere el 27 de febrero de 1964, apenas unos días después de presentar el primer libro, del que era autor. En marzo de ese mismo año se constituirá legalmente la editorial, tras diversas reuniones preparatorias.

\section{Publicación de Libros}

De la inicial publicación de dos folletos, escritos por los propios militantes, se pasaría pronto a una producción superior a los cinco millones de pesetas anuales, a pesar de las continuas trabas y secuestros por parte de la administración franquista. El precio de venta (20 pesetas para la serie roja y 13 para la serie verde) se mantendría durante años, con las consiguientes dificultades económicas con las que tal empeño tropezaba, por ejemplo en el desequilibro existente entre el precio de coste y el mantener los precios a niveles de los bolsillos obreros. De la tarea de la editorial cabe destacar:

a) La originalidad y la profundidad con que fueron extendiéndose sus libros. Por primera vez en España aparecen "puestos de libros" con contenido y títulos que desde el punto de vista político y social resultaban insólitos y para algunos, insultantes (un alto militar se quejó a la administración de "que todos los días al salir de su casa, tenía que desayunar con Bakunin, Pestaña o Marx”). Estos puestos, atendidos por militantes y simpatizantes, estaban en cualquier calle, a cualquier hora; en cualquier puerta de fábrica, facultad o universidades, siendo a la vez 
que "un grito" en la calle, una pesadilla para muchas autoridades municipales y sectores ultras y reaccionarios.

b) La creación de una red de difusión: las delegaciones, que a veces comenzaron a funcionar con el esfuerzo inicial de una sola persona, pronto llegaron a ser el corazón y la base ZYX. A este respecto, un alto funcionario extranjero llegó a decir "que no hay más que dos formas de llevar a cabo una obra semejante: con muchos millones o con una mística fuerte y auténtica".

Los criterios para las publicaciones serán: a) publicar todo aquello que pueda aportar conocimiento histórico experimental de la lucha obrera, servicio al frente obrero; b) no identificación con ningún grupo concreto; c) redacción y publicación de pensamiento propio; d) no hay ninguna razón para dar paso a ningún criterio que plantee que la religión católica o la Iglesia son alienantes sino al contrario.

\section{Principios, Razones y Finalidades de su Existencia}

La editorial ZYX se asentaba en los siguientes principios: a) Confianza mutua: la autodisciplina y la entrega sustituyen a la disciplina impuesta y a la consigna en el quehacer. b) Atención preferente las zonas más pobres y desatendidas del territorio nacional. c) Nada de compromisos ni alianzas que puedan suponer o supongan, una hipoteca a la libertad y a la autodeterminación ideológica, organizativa o táctica. d) Absoluta independencia económica.

Las razones del nacimiento de la editorial son variadas y complejas, aunque podrían resumirse en cinco, como expone Don Tomás Malagón en la citada carta a Monseñor Benavent (Malagón, 1999): a) La voluntad de actuar sin la salvaguarda, pero también las limitaciones, de la Acción Católica. b) La necesidad de una formación y de una acción cada vez más comprometida. c) El deseo de acercamos a otros obreros y a otros conjuntos humanos, para trabajar, a ser posible, con una mayor unión o coordinación entre todos. d) El afán, sobre todo, de servir de un modo más eficaz a la promoción del pueblo. e) Según se expresa en una circular de debate e información interna del 31 de diciembre de 1970, respecto a la promoción cultural del pueblo: "la 


\section{Araus y Sánchez - Editorial ZYX}

concebimos como capacitación ideológica del pueblo y como desarrollo de un modo de ser y actuar comunitarios del mismo en todos los planos: económico, sindical, político y religioso".

La Editorial ZYX tuvo como finalidad la promoción integral y colectiva del pueblo. Por promoción entendía el cultivo y el desarrollo de las capacidades de la persona, lo cual requiere la acción; no se trata de favorecer promociones personales, que son casi siempre evasión y desclasamiento, sino de impulsar la promoción colectiva del pueblo como conjunto de personas que carecen de las necesidades más básicas. Además, esta promoción debe de ser integral, referida a todos los aspectos (económico, social, político, cultural, humano). Para que esto sea posible es necesario: a) Una gran labor cultural popular, que, además del análisis del mundo actual, signifique una profunda concienciación socio-política del pueblo. b) Formación adaptada a los militantes. c) Creación por esos grupos de las asociaciones políticas, sindicales y de opinión necesarias para la acción. d) Fomentar entre las diversas tendencias dentro del mundo obrero la mayor colaboración posible.

Para hacer realidad todos estos fines ZYX dirige su labor especialmente a los siguientes sectores: a) El sector obrero y campesino, contribuyendo a la creación de aquellos equipos militantes que el mundo del trabajo necesita. b) Al sector de sacerdotes y seminaristas, a los cuales la editorial trata de facilitar orientaciones ideológicas y pastorales para la actuación en el campo obrero y campesino. c) El sector universitario es también tenido en cuenta por la editorial a causa de su interés por los problemas sociales y los temas ideológicos que puedan fundamentar la promoción del pueblo. d) Los maestros nacionales también son objeto de especial atención por la editorial por su necesidad de promoción material y profesional y su vinculación al pueblo, además de su labor en la enseñanza y educación en el mundo del trabajo.

La editorial ZYX no se impone ninguna frontera geográfica de actuación: se extendió por toda España, además de las zonas de Europa que tenían una fuerte emigración española y también se extendió por algún país de Iberoamérica (Santiago de Chile). 


\section{HSE - Social and Education History, 4(3) 281}

\section{Otros Medios para la Formación de Conciencia}

ZYX contó con una serie de medios para formar una conciencia de servicio y fidelidad al pueblo, además de suscitar militantes y aglutinar grupos. Son especialmente destacables, a parte de las publicaciones ya analizadas, los cursillos, clubs de lectores y sociedades culturales que señala, a modo de ejemplo, Don Tomás Malagón en la citada carta a Monseñor Benavent (Malagón, 1999):

a) Cursillos para militantes: a estos cursillos, que se celebraban por toda España, podían asistir quienes lo desearan, sin más requisito que someterse a las condiciones del curso que se señalara en cada caso. Quien organiza estos cursillos no es ZYX, son siempre teleclubs ${ }^{10}$, obras apostólicas, sociedades culturales, etc.; se trata de cursillos celebrados generalmente por las noches o en fines de semana, sobre diversos temas.

b) Cursillos de Orientación: especialmente destinado a aquellos que han llegado a ZYX sin pasar por la HOAC ni por cursillos apostólicos, pero que necesitan plantearse el problema cristiano.

c) Cursillos de Iniciación Militante: para la formación humana y la creación del espíritu necesario para realizar la labor como militantes de ZYX.

d) Ejercicios Espirituales para militantes: para facilitar a cuantos colaboran en la ZYX los medios de espiritualidad adecuados (aunque estos ejercicios podrían darse también a otras personas)

e) Cursillos técnicos: de sindicalismo, de política y de economía.

f) Cursillos para sacerdotes y seminaristas (pastoral, compromiso temporal, teología social, marxismo,...)

g) Cursillos para educadores: fundamentalmente son cursillos de orientación ideológica y pedagógica

h) Cursillos para Universitarios: de ateísmo contemporáneo y de orientación

i) Cursillos para directores de Cursillos

j) Clubs de lectores: ante diversos grupos de obreros los responsables de ZYX en las distintas zonas de España hacen la presentación de las publicaciones, explicando la temática y el desarrollo de los libros. 


\section{Araus y Sánchez - Editorial ZYX}

k) Sociedades culturales: los militantes de ZYX tratan de ir creando, donde es posible, centros de irradiación de una conciencia y cultura verdaderamente popular.

\section{Conclusión}

Dado que ZYX perteneció a una corriente apostólica claramente opuesta a la que identificaba Iglesia-Derecha, prestó un gran servicio a la sociedad española, pues desgraciadamente contaba con pocas organizaciones de este tipo dentro del mundo obrero. Pretendió la evangelización del pueblo, no desde el paternalismo o la acción asistencial, sino desde la promoción y el protagonismo del pueblo.

Para muchas personas, tanto de izquierdas como de derechas les fue difícil entender lo que era la editorial ZYX. La identificación IglesiaDerecha política era, sobre todo para la oposición y exilio de izquierdas, algo absoluto y lo tenían como algo indiscutible. No se explicaban que en una editorial puesta en marcha por militantes cristianos publicaran continuamente obras de todas las corrientes que habían hecho posible el movimiento obrero. En este sentido cabe destacar las palabras de Heleno Saña, militante libertario:

La Editorial ZYX fue la plataforma que permitió recuperar la memoria histórica de lo que había sido el movimiento obrero, no solamente libertario, sino el movimiento obrero y sindicalista español. Y para mí, a parte de mi vinculación personal a la editorial, a parte del afecto que le he tenido siempre, pues significa un proyecto editorial realizado que ha sido el más importante que ha tenido España. La prueba es que una vez finalizado este proyecto, no ha sido sustituido y ha quedado un vacío enorme. Vacío que naturalmente coincide con el encanallamiento político y cultural del país. Y este es el recuerdo que tengo yo de la editorial. Lo que más me impresionó como libertario es que era una cosa organizada por cristianos vinculados al movimiento obrero y publicando la cultura libertaria y socialista. Fue en toda regla un experimento único en la época del franquismo” (Saña, 1999). 
Francisco Rojas (2006) señala que "la editorial ZYX representa uno de los ejemplos más notables de cómo una editorial se convierte en plataforma de lucha contra el régimen, desde unos presupuestos eminentemente religiosos que en ningún momento abandonaría", aunque esta última matización habría que analizarla desde la crisis que sufrió la editorial, a los diez años de su nacimiento.

Ministros de gobiernos socialistas, tanto a nivel estatal como regional, altos cargos socialistas del congreso de los diputados, altos dirigentes de sindicatos hegemónicos y de base, catedráticos de universidad e institutos, promotores de partidos y sindicatos autogestionarios, de cooperativas y asociaciones de vecinos, de centros de cultura y enseñanza tuvieron que ver con la asociación de ZYX.

Tuvo, la editorial, una repercusión enorme y después de su ruptura, algunos militantes siguen en la lucha. Posteriormente se creará el MOA (Movimiento Obrero Autogestionario), con el fin de servir de puentes entre la UGT y la CNT, para que el sindicalismo autogestionario resucitara y, con él, el sindicalismo revolucionario. En 1980 se lanza un movimiento de promoción militante, el Movimiento Cultural Cristiano: movimiento laico de apostolado privado, de cara a que en un largo plazo de la vida española siga habiendo militantes que no se conformen con una democracia formal, sino construir una democracia real y trabajen por la promoción personal y colectiva e intenten romper el poder del imperialismo transnacional para construir una sociedad autogestionaria.

Más de un millón de libros publicados, sin subvención ninguna y centenares de cursos de formación militante con la misma base económica, hicieron posible esta aportación a la democracia española, a pesar del Estado, colaborando a tender puentes de paz entre las dos Españas. 


\section{Araus y Sánchez-Editorial ZYX}

\section{Notas}

${ }^{1}$ Periódico semanal de Buenos Aires lanzado el 13 de junio de 1897 por un grupo de obreros, y que muy pronto se convertirá en el órgano central del movimiento obrero argentino.

2 La cuestión obrera está presente en el seno de la Iglesia Católica, aunque será desde la publicación de la Rerum Novarum en 1891 cuando cobre mayor fuerza. Ver Rerum Novarum, 1 .

${ }^{3}$ ECLESSIA. 4 DE MAYO DE 1946. Las "Normas generales para la especialización obrera de la Acción Católica Española",fueron publicadas por Monseñor Vizcarra y darían lugar a las ramas especializadas obreras de HOAC y JOC

4 ARCHIVO DEL GOBIERNO CIVIL DE VIZCAYA. «Penúltima hoja informativa», con fecha de mayo de 1967. La huelga más larga durante el franquismo. En esta huelga, especial atención merece el papel desarrollado por la Iglesia. A lo largo del conflicto se produjo un gran apoyo por una gran parte de las parroquias de la zona. Grupos católicos como la HOAC y la JOC desarrollaron un papel fundamental en la organización de la huelga, hasta tal punto que la configuración del conflicto e incluso el propio movimiento obrero vizcaíno resultaría incomprensible sin este elemento... existe constancia de apoyo económico al mantenimiento de la huelga, tal y como se desprende de los servicios de información de la Guardia Civil, introducidos en diversas reuniones dentro de las propias parroquias. Ver HOJA INFORMATIVA DEL AGCV, febrero 1967, titulada A los trabajadores, donde se cita la entrega de diversas cantidades económicas por medio de militantes a la HOAC. Cf. PÉREZ, J. A., "La huelga de Bandas: Del conflicto laboral y el nacimiento de un símbolo", en Dialogando con Euskadi. Madrid: Voz de los Sin Voz, pp. 21-41.

5 Proveniente del anarcosindicalismo. Su conversión, aparece en forma de relato en "Mis recuerdos de Rovirosa", Boletín monográfico dedicado a Guillermo Rovirosa Albert, promotor de la HOAC, correspondiente a los meses de mayo y junio de 1964. Pg. 21-25

${ }^{6} \mathrm{El}$ desarrollo de las etapas de la editorial está tomado de un folleto publicado hacia 1978; hay que tener en cuenta en él que no sólo se ha producido un cambio de nombre (en 1969), sino una grave crisis y escisión, que entre 1972 y 1974 produjo un giro considerable en los principios fundamentales de la misma, por motivos fundamentalmente políticos, que dieron al traste con la organización y la tarea apostólica con las que nació ZYX.

${ }^{7}$ De la misma manera que fueron militantes de la HOAC los que lanzaron ZYX, fue la existencia de ZYX la que forzó que a la HOAC se le concediera un Estatuto especial, en 1966, dentro de la Acción Católica española, ligándose directamente a la Comisión Episcopal de Apostolado Seglar.

${ }^{8}$ Aunque algunos erroneamente defiendan que la editorial se crea aprovechando dicha Ley Fraga, como hace José Miguel Oriol en la reciente presentación de sus memorias, en el 30 aniversario de la fundación de la Editorial encuentro.

${ }^{9}$ Lo que después el Código de Derecho Canónico denominará Asociación Privada de Fieles 
10 "En España el 6 de abril de 1964, la Junta Central de Información y Turismo adoptó la decisión de poner en marcha una red de teleclubs experimentales, el 25 de noviembre del mismo año, el Subsecretario del Ministerio de Información y Turismo presidió la inauguración del primero de la RNT (Red Nacional de Teleclubs) en Motilla de la Seca, Zamora. En el mes de diciembre de ese año se habían constituido 26 teleclubs pasando a ser más de 300 en 1965 y 1.113 en 1966" (Cantero, 2006, p.108).

\section{Referencias}

Abad de Santillán, D. (1977). Memorias: 1897-1936. Barcelona: Planeta. Aguado, F., Molina, Ma.P. y García, Ma.A. (1977). Por qué luchamos los trabajadores. Lecciones para una escuela de formación obrera. Madrid: Zero.

Araus, Mª. M. (1998). Relaciones entre el movimiento obrero español y el iberoamericano: 1860-1920. Madrid: Voz de los sin Voz.

Arbeloa, V. M. (1992). Militantes obreros. Madrid: Voz de los Sin Voz, Madrid.

Berzal de la Rosa, E. (1999). Del nacionalcatolicismo a la lucha

antifranquista. La HOAC de Castilla y León entre 1946 y 1975. Tesis

doctoral dirigida por Pedro Carasa. Universidad de Valladolid, Facultad de Filosofía y Letras.

Cantero, C. (2006). "Equipamientos culturales de proximidad en España en el siglo XX. Los Teleclubs" Periférica, 6 .

Cisquella, G. (2002). La represión cultural en el franquismo. Diez años de censura de libros durante la Ley de Prensa (1966-1976), Barcelona: Anagrama.

Díaz, C. (1996). España, canto y llanto. (Historia del movimiento obrero con la Iglesia al fondo). Madrid: Acción Cultural Cristiana.

Díaz del Moral, J. (1973). Historia de las agitaciones campesinas andaluzas. Madrid: Alianza Editorial.

García, X. (1990). Rovirosa, precursor del apostolado organizado de iniciativa privada. Imágenes de la fe, 242, 22-25.

Gómez del Castillo, J. (1987). Apostolado militante: Ayer y mañana. Madrid: Voz de los Sin Voz. 
Gómez del Castillo, J. (1996). Editorial ZYX. AUTOGESTIÓN, 13, p. 28. López, B. (1995). Aproximación a la historia de la HOAC (1946-1981). Madrid: HOAC.

Malagón, T. (1999). Carta que D. Tomás Malagón escribió al arzobispo de Granada D. Emilio Benavent sobre lo que era la editorial ZYX. ID Y EVANGELIZAD, 16, nov. 1999, 26-31

Meert, J. y Malagón, T. (1968). Cardijn. Madrid: ZYX.

Navarro-Ruiz Camps (1993). TÚ, periódico apostólico obrero. Madrid: XX Siglos.

Oriol, J.M. (2008). 30 años de Encuentro. Memorias de una experiencia editorial. Madrid: Encuentro.

Pérez, J.A. (1999). Dialogando con Euskadi. Madrid: Voz de los Sin Voz.

Pérez Rey, T. (1970). La editorial: nacimiento y evolución. Conferencia impartida en la Asamblea de ZYX de febrero de 1970.

Rojas, F. (2006). Poder, disidencia editorial y cambio cultural en España durante los años 60. Pasado y memoria, 5, 67-68.

Rovirosa, G. (1995). Obras completas. Vol II. Cooperación y comunidad. Madrid: HOAC.

Rovirosa, G. (2007). Obras completas VI. Cartas. Madrid: HOAC.

Saña, H. (1998). Autogestión y Cultura. La cultura proletaria. Madrid: Voz de los sin Voz.

Saña, H. (1999). Entrevista a Heleno Saña. AUTOGESTIÓN, 30. Octubre 1999.

Ma del Mar Araus, Doctora en Historia. Universidad de Alcalá.

Ana Sáchez, Universidad de Valladolid.

ORCID: orcid.org/0000-0003-1574-6158

Contact Address: ana.sanchez.velasco@uva.es 